\title{
Una nova proposta d'identificació de l'«alqueria mia per nom Xilvella» de la crònica de Ramon Muntaner: les Cases de Bàrcena, al nord de la ciutat de València
}

\section{A new proposal to identify «my farm called Xilvella» of the chronicle of Ramon Muntaner: Les Cases de Bàrcena, north of the city of Valencia}

Vicent Baydal SALA baydal@uji.es Universitat Jaume I

FERran Esquilache Martí esquilac@uji.es Universitat Jaume I

Resum: Tradicionalment s'ha identificat l'«alqueria mia per nom Xilvella» on comença la crònica de Ramon Muntaner amb l'actual municipi de Xirivella, al sud de la ciutat de València, tot i que alhora sempre s'han mantingut dubtes, atesa la manca de proves documentals que ho confirmaren i l'existència d'algunes que ho desmentien. En el present article proposem una altra localització per a l'alqueria de Ramon Muntaner: l'explotació rural que apareix al Llibre del Repartiment de Jaume I com a Xilvella al-Xarquia, en l'actual pedania de les Cases de Bàrcena, al nord de la mateixa ciutat de València. Diversos indicis documentals i paisatgístics així ho assenyalen.

Paraules clau: Ramon Muntaner, Xilvella, Les Cases de Bàrcena, Xirivella, cròniques

\begin{abstract}
My farm called Xilvella" where Ramon Muntaner's chronicle begins has been traditionally identified with the current municipality of Xirivella, south of the city of Valencia, although at the same time doubts have always remained, given the lack of documentary evidence to confirm it and the existence of some to disprove it. In this article we propose another location for the farm of Ramon Muntaner, that is, the rural area that appears in the Llibre del Repartiment of James I as Xilvella al-Xarquia, in the current term of Les Cases de Bàrcena, a district north of the same city of Valencia. Several documentary and landscape indications point this out.
\end{abstract}

Keywords: Ramon Muntaner, Xilvella, Les Cases de Bàrcena, Xirivella, chronicles

\footnotetext{
* El present article s'insereix en el marc del treball desenvolupat en el projecte «La gestió de l'herència agrària andalusina. Modificacions i transformacions realitzades en els espais irrigats del Regne de València després de la conquesta cristiana (segles XIII-XVI)», finançat per la Universitat Jaume I i coordinat pel grup d'investigació «FORVAL. Història i Dret Forals Valencians» de la mateixa Universitat Jaume I de Castelló.
} 
«E estant jo en una alqueria mia per nom Xilvella, que és en la orta de València» (Aguilar 2015: II, 17). Així comença una de les cròniques medievals catalanes més conegudes i atraients, la de Ramon Muntaner, qui la va escriure entre el 1325 i el 1328, quan justament residia a la ciutat de València, tot involucrant-s'hi en els seus afers públics i privats (Cingolani 2015). En aquest sentit, des de fa molt de temps aquella referència iniciàtica a la seua possessió rural s'ha atribuït a la localitat de Xirivella, a la comarca històrica de l'Horta Sud, a pocs quilòmetres al sud-oest de la capital valenciana, segons es pot veure en la Figura 1, i amb vora 30.000 habitants en l'actualitat. Amb tot, l'atribució ha generat també certes reticències, com les que va fer a final del segle XIX Pròsper de Bofarull (1883: 48), en dubtar-ne «ya por no haber visto dato alguno que pruebe este señorío, ya por ser nombre que se escribe de diversa manera, no pudiendo deslindarse de qué territorio ó poblacion formase parte el supuesto señorío». En efecte, el senyoriu o la possessió de la localitat de Xirivella per part de Ramon Muntaner mai no han estat provats, sinó tot al contrari, i és molt més probable que, per contra, l'aventurer de Peralada, segons tractarem de mostrar a continuació, tinguera una simple alqueria, casa de camp o explotació agrària anomenada Xilvella -com diu exactament la crònica- que es trobava en un altre lloc, en el que hui són les Cases de Bàrcena, a l'Horta Nord, també a pocs quilòmetres de la ciutat de València, de la qual actualment és una pedania de 400 habitants. ${ }^{1}$

\section{El difícil encaix de l’alqueria de Xilvella en la localitat de Xirivella, al sud de València}

Qui ha tractat de manera més precisa la qüestió de la difícil identificació de l'alqueria de Xilvella ha estat Mateu Rodrigo (2019: 39-42), de qui, per tant, resumirem les dades de la seua completa síntesi, la qual comença advertint que «sempre ha estat problemàtic establir el caràcter de la més important, segons sembla, de les possessions territorials de Muntanen. En aquest sentit, com apunta, no hi ha cap dubte que el topònim baixmedieval Xilvella/Chilvella/Gilvella -un diminutiu del llatí silva, bosc- va evolucionar amb el temps al de Xirvella/Chirvella/Girvella i finalment a Xirivella/Chirivella/Girivella, segons va demostrar, per una altra banda, Miguel Sorribes (1989: 25-27), amb un detallat recull cronològic que indica que el canvi lingüístic es va començar a produir a partir del segle XVII. Les objeccions a la vinculació de la Xilvella de Muntaner amb la Xirivella de la comarca històrica de l'Horta Sud, per contra, són altres. En primer lloc, que aquesta no era una casa de camp o explotació agrícola, sinó una població d'una grandària gens menyspreable, amb 43 cases contribuents en les llistes de l'impost del morabatí més antigues que es coneixen, les del 1379, per la qual cosa la referència literal de la crònica -«una alqueria mia per nom Xilvella»- resultaria del tot inexacta. En segon lloc, no coneixem documents de l'època que confirmen la possessió de la Xirivella meridional per part de Ramon Muntaner, sinó que contràriament la descarten, «i aquest és el principal motiu de dubte», segons indica el mateix Rodrigo (2019: 40).

En efecte, ja uns mesos abans de la conquesta cristiana de la ciutat de València, pel febrer del 1238, Jaume I va concedir al comanador d'Alcanyís, de l'orde militar de Calatrava, l'«alqueriam de Chilbella del Algarbia, cum furnis et molendinis», segons es consigna als registres del Llibre del Repartiment (Ferrando 1979: doc. 2.213), en aquest cas fent referència a una alqueria andalusina (al-qarya) en el sentit que tenia en aquells

\footnotetext{
1 Som ben conscients de les grans implicacions a escala local que té la nova proposta d'ubicació de l'alqueria on es va gestar la crònica de Ramon Muntaner, atés que en l'actual població de Xirivella hi ha tot un seguit de vinculacions institucionals i cíviques amb la seua figura. Tanmateix, és evident que no podem deixar de plantejar-la, puix que la considerem suficientment provada i resol una problemàtica historiogràfica de molt llarg recorregut.
} 
moments, és a dir, no com una explotació agrària unifamiliar, sinó com una aldea o nucli de població conformat per diverses cases i famílies, amb el seu terme $\mathrm{i}$ instal lacions inherents, com ara els forns $\mathrm{i}$ els molins (Guichard 2001). Cal destacar, d'altra banda, que el mateix repartiment distingeix entre allò que els musulmans anomenaven Xilvella al-Garbia, o Xilvella de Ponent, que era aquesta, la de l'Horta Sud, i una altra Xilvella al-Xarquia, o Xilvella de Llevant, situada a l'actual Horta Nord, les dues dites així en relació amb l'orientació dels punts cardinals islàmics, que s'ordenaven en funció de la ubicació de la Meca, en aquest cas situada al sud-est de la ciutat de València (Ribera 1952, Epalza 1988: 49). ${ }^{2}$ I, més enllà de la donació reial primigènia, la possessió senyorial per part de l'orde de Calatrava de Xilvella al-Garbia, és a dir, de la localitat de Xirivella, es documenta de manera ininterrompuda durant vora un segle i mig, fins a la dècada del 1380, incloent sense lloc a dubte el temps que Ramon Muntaner va viure a terres valencianes (Rodrigo 2019: 40).

Amb tot, malgrat l'absoluta manca de proves coetànies de la vinculació del cronista a la Xirivella de l'Horta Sud, ja des de la segona meitat del segle XV es troben afirmacions que el semblen fer senyor de la localitat, començant pel testament del seu net homònim, publicat el 1468 segons el cronista dominic Jaume Falcó, qui durant la primera meitat del segle XVII en va transcriure l'únic fragment conegut, en què es deia que l'esmentat descendent volia sepultar-se a la capella de Sant Macari del convent de predicadors de la ciutat de València, «hon està soterrat mon pare Machari Montaner y en la qual està tanbé soterrat mon avi Ramon Montaner, señor qui fonch del lloch de Chilvella». ${ }^{3}$ Igualment, també altres esments dels segles XVI i XVII afirmen que el cronista va exercir com a senyor de la localitat, com la indicació del cronista Pere Antoni Beuter (1538: IIIr) sobre les seues fonts -«del temps de l'ínclit rey en Jaume fins als dies de hui me só aprofitat dels libres de mossén Montaner, senyor de Chilvella»-, l'acord pres pels jurats de València el 1555 per tal de sufragar una impressió de la crònica del «quòndam señor del lloch de Chilvella» (Serrano Morales 1898-1899: 300) o les consideracions de diversos autors sis-centistes com Francesc Diago (1613: llib. VII, cap. LXVI, f. 390r), qui va afirmar que: «Vínose después Ramón Montaner a este Reyno, y siendo señor de Xirvella compuso en ella su Historia».

En aquest sentit, de fet, la postura d'un altre autor d'aquesta mateixa època, Gaspar Escolano, per tal de superar la contradicció entre l'atribució a Muntaner de la senyoria de la Xirivella de l'Horta Sud i les dades irrefutables conegudes sobre la pertinença continuada de la localitat a l'orde de Calatrava és la que pren l'esmentat Mateu Rodrigo en el seu tractament de la qüestió. En concret, Escolano (1611: llib. VII, cap. III,

2 És cert que hi ha historiadors de la localitat que han volgut situar els dos nuclis esmentats al Llibre del Repartiment com a barris veïns dins de l'actual terme municipal de Xirivella (Soria \& Gordón 2014), però per als historiadors que coneixen bé aquesta font i la geografia de l'Horta de València (Guinot 2007: 177; Frechina, Sales, Mangue \& Ferrer 2007; Sales 2015; Esquilache 2016: 71) no hi ha cap dubte sobre la distància separada per molts quilòmetres d'ambdós nuclis, ja que l'esmentat registre situa Xilvella al-Xarquia «iuxta Nacarella» que, com veurem, era un altre punt diferent, a l'Horta Nord.

3 Biblioteca Històrica de la Universitat de València, Ms. 204, Historia de algunas cosas más notables pertenecientes a este convento de predicadores de Valencia, compuesta por el muy reverendo padre fray Jayme Falcó, predicador general, bijo de bábito de este convento. Renuévala por orden del muy reverendo padre presentado fray Vicente Inza, prior de dicho convento, su más indigno súbdito el padre fray Luis Carbonell, bijo de dicha casa en el año del Señor de 1720, f. 46. En relació amb això, Mateu Rodrigo (2019: 40) afirma que la datació el 1468 seria «un gras error cronològic», però un procés judicial iniciat el 1653 contra el cavaller Jeroni Ramon Montaner, descendent del cronista, sobre les despeses inherents a aquella mateixa capella del convent de predicadors indica igualment que el testament del net es va publicar «en vint-y-tres de setembre de l'any mil quatre-cents sexanta-yhuit»: Arxiu del Regne de València (ARV), Reial Audiència, Processos, Part I, Lletra R, núm. 202. Certament seria molt atípic que Ramon Muntaner morira el 1336, el seu fill Macari el 1394, com veurem després, i el seu net Ramon el 1468, però és el que indiquen els esments documentals coneguts. 
col. 304) va indicar que: «Xilvella (...) perteneció a la orden de Calatrava. Después la posseyó el buen cavallero Ramón Montaner, y a lo que entiendo en razón de algun empeño o asiento que hizo con él la Religión». I, en consonància amb això, Rodrigo (2019: 41) reforça l'argument fent un paral lelisme amb el que va succeir amb el primer canvi de domini senyorial documentat a Xirivella, atés que el 1386 l'orde de Calatrava va alienar durant onze anys la senyoria útil al cavaller Ramon Boil fins que finalment va traspassar la jurisdicció plena a la família, que la va mantindre fins a l'abolició de l'Antic Règim. ${ }^{4}$ Tanmateix, no ha estat documentat cap negoci semblant de l'orde amb el cronista i, en cas d'haver-se produit, això difícilment hauria generat les paraules concretes que Muntaner va deixar escrites sobre «una alqueria mia per nom Xilvella».

No debades, precisament per aquesta raó altres autors de la història local de Xirivella han optat per considerar que el que posseiria Ramon Muntaner seria exclusivament una casa rural o alqueria unifamiliar dins del terme del municipi (Sorribes 1989: 142-146), encara que això tampoc coincidisca amb la literalitat de les seues paraules, ${ }^{5}$ o, fins i tot, d'una part del senyoriu, l'oriental o Xilvella al-Xarquia (Soria \& Gordón 2014: 78), malgrat estar ben demostrat que aquest topònim es corresponia en l'època amb un altre nucli allunyat i situat a diversos quilòmetres al nord de la ciutat de València (Baydal \& Esquilache 2020: 23-32). En definitiva, existeix una altra raó per la qual hi ha tanta contradicció i tan difícil encaix entre la teòrica possessió senyorial de Muntaner del lloc de Xirivella de l'Horta Sud, o d'una alqueria dins del seu terme, i la realitat dels textos i documents disponibles de la seua època: molt probablement el que posseïa el cronista era la Xilvella del nord, una explotació agrícola de reialenc que en l'actualitat s'ubica en la pedania de les Cases de Bàrcena, pertanyent al districte dels Poblats del Nord del terme municipal de la ciutat de València, segons es pot observar en l'esmentada Figura 1.

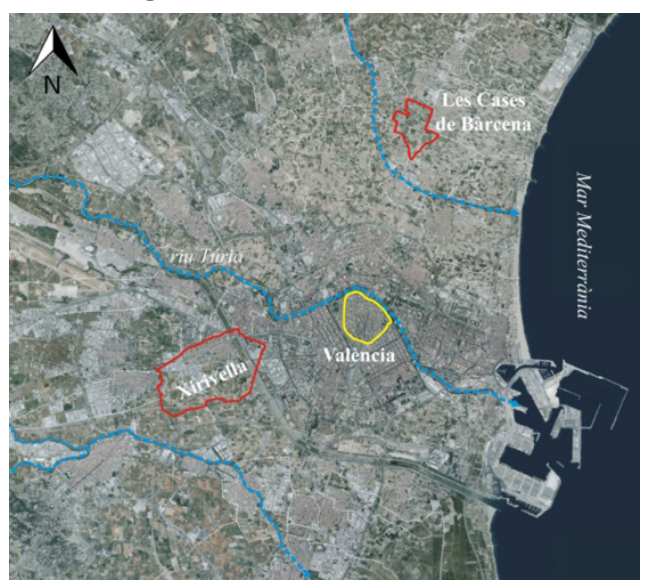

Figura 1. Plànol de situació de la pedania de les Cases de Bàrcena i de l'actual municipi de Xirivella respecte del nucli històric de la ciutat València.

\footnotetext{
4 També Francesc Almarche (1909: 485) va asseverar que «està fora de dubte que Muntaner, per part de la seua muller fón propietari del loch de Xirivella de Ponent, ignorantse per ara ahon estaría Xilbella de la Axarquia, y creen que el domini superior estaría en mans de la Orde de Calatrava sent senyor Muntaner en lo que no tocava a exe dret, que precisament sería el que fóu venut o donat a D. Pere Boyl», però sense aportar cap document ni font que provara tal afirmació.

5 El mateix Mateu Rodrigo (2019: 41-42) també contempla aquesta possibilitat, que relaciona amb l'existència a final del segle XIX de dues alqueries entre els termes municipals de València i Xirivella anomenades «de Chirivella» $i$ «de Chirivelleta», però acaba decantant-se per l'opció d'algun acord amb l'orde de Calatrava sobre el senyoriu de la localitat sencera, a la qual cosa cal afegir que amb molta probabilitat les esmentades alqueries deuen el seu nom a la pertinença a famílies amb el cognom «Chirivella» ja en època moderna o contemporània.
} 


\section{Xilvella al-Xarquia, un emplaçament que encaixa amb la possessió rural de Ramon i Macari Muntaner}

Com apunta l'esmentat Mateu Rodrigo (2019: 42), durant la seua residència estable a València entre el 1315 i el 1333 Ramon Muntaner «no va gaudir d'una gran fortuna personal, malgrat posseir alguns predis rurals (...) i propietats urbanes modestes». En concret, indica que tenia certs immobles a la ciutat de València dels quals rebia censos, així com dues cases i un obrador situats al raval de la Moreria pel 1321, alhora que posseïa l'alqueria d'Aitona al terme de Corbera pel 1325 - permutada un poc més tard per la Torre d'en Romaní en l'actual terme de Sollana- i l'alqueria de Beniferri amb sis cafissades de terra al terme de València pel 1330, quan la va vendre per 9.000 sous al mercader Ramon de Moyó. I el mateix Rodrigo (2019: 39) destaca que aquestes possessions rurals eren alqueries en «el sentit de domini rústic menor, més o menys extens, centrat en una edificació per a residència i usos agraris», la qual cosa s'allunya novament de la possible possessió de la senyoria de la localitat de Xilvella/Xirivella, a l'Horta Sud, fos en les condicions que fos.

Per contra, com hem indicat, existeix una altra Xilvella/Xirivella que s'adiu perfectament tant a les característiques generals del patrimoni immobiliari de Ramon Muntaner com a les seues paraules en la crònica: la Xilvella alXarquia que apareix al Llibre del Repartiment com un domini dins del terme i horta de València. En concret, dos són els únics esments que hi fan referència clara: la concessió el 28 de juliol del 1238 als tortosins Joan d'Alfocea i Bernat d'Alfocea de l'«alqueriam de Xilbela de la Xarquia, iuxta Naquerella, cum terris ad sex paria bovum et singulos ortos in alqueria» $\mathrm{i}$ la feta al cavaller Ponç de Montsoriu un poc després, el 20 d'agost, de 10 jovades a Nacarella i les «domos Mahomat Atarraç Xilbella de la Xarquia» (Ferrando 1979: doc. 541 i 655). En aquest cas, doncs, a diferència de la Xilvella de l'Horta Sud, concedida íntegrament a un important senyor, l'orde de Calatrava, amb tots els seus forns i molins, tot apunta que la Xirivella del nord es tractava d'una possessió més menuda, repartida a dos veïns de Tortosa amb sengles horts i una porció de terra concreta, ${ }^{6}$ on hi havia també algunes cases a l'entorn, com la de «Mahomat Atarraç». Igualment, un altre possible indici de la relativa petitesa de la possessió en el context de l'horta de València és que, a més d'indicar-se que era la Xilvella «de la Xarquia», apareixia en els dos esments relacionada amb Nacarella, un terme adjacent -habitualment dit Macarella-, que servia així de referència per a la seua ubicació.

De fet, la reconstrucció del paisatge agrari irrigat del moment de la conquesta cristiana que permeten les tècniques de prospecció del sistema hidràulic bastit per la Séquia de Montcada indica que la de Xilvella alXarquia era una petita horta construïda pels andalusins en aquesta zona del nord de la ciutat de València, en els contorns de l'antiga Via Augusta -després Camí Reial de Morvedre-, segons es pot observar en la Figura 2, feta a partir de detallades anàlisis ja publicades in extenso (Baydal \& Esquilache 2020: 15-41). Concretament, a partir de la identificació dels característics espais agraris irrigats

6 Les «terris ad sex paria bovum» fan referència a terres per a sis parelles de bous, és a dir, a 6 parellades, la mesura que en teoria indicava la terra que una parella de bous pot llaurar en una jornada. Amb tot, les indicacions sobre les parellades al llarg dels segles XII i XIII són canviants segons la zona, per la qual cosa no coneixem amb certesa la seua equivalència amb el sistema mètric decimal (Bolós 1993-1994, Riu 1996: 833, Sarobe 1998, Eritja 1998: 68). Per les mesures detectades a les zones de la Catalunya Nova, tal vegada - tot i que no és en absolut segur-cada parellada podria equivaldre a 9 cafissades, per la qual cosa la quantitat de terra concedida amb Xilvella al-Xarquia serien 54 cafissades o 9 jovades, és a dir, unes 26,91 hectàrees.

$7 \mathrm{Al}$ Llibre del Repartiment encara hi ha una altra referència a «quamdam vineam in Silbella» atorgada l'1 d'agost del 1240 a Adam Tender, juntament amb 2,5 jovades a Russafa (Ferrando 1979: doc. 1381). És probable que fera referència a aquesta Xilvella al-Xarquia de l'Horta Nord, al costat de Nacarella, atés que l'altra Xilvella ja era possessió senyorial de l'orde de Calatrava des de dos anys abans. En tot cas, continuaria indicant la relativa petitesa d'un lloc del qual es repartien unes poques cases, horts i terres. 
Vicent Baydal \& Ferran Esquilache. Una nova proposta d'identificació de l'«alqueria mia per nom Xilvella» de la crònica de Ramon Muntaner: les Cases de Bàrcena, al nord de la ciutat de València

campaniformes i piriformes dels andalusins, s'hi pot veure que hi havia tres hortes properes vinculades a tres nuclis distints, que tindrien els seus propis termes: de sud a nord, les de Carraixet -a partir del segle XV anomenat Bonrepòs i Mirambell-, amb unes 18 hectàrees irrigades, Xilvella al-Xarquia, amb unes 12 hectàrees de regadiu, i Nacarella/Macarella, amb unes 8 hectàrees de reg. Amb tot, a partir de l'ocupació cristiana del 1238 l'evolució d'aquests tres nuclis i termes va ser distinta, segons es pot inferir de la documentació disponible a partir d'aleshores. ${ }^{8}$

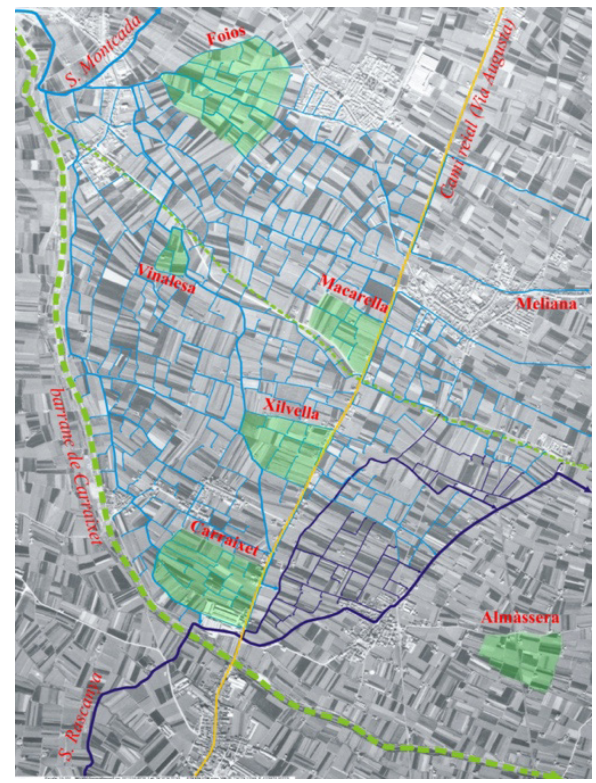

Figura 2. Reconstrucció del sistema hidràulic de la Séquia de Montcada al voltant de les Cases de Bàrcena sobre una fotografia aèria del 1945 i identificació dels espais irrigats andalusins presents a la zona anteriors a la conquesta cristiana de Jaume I. Font: Baydal \& Esquilache 2020.

En primer lloc, si bé Carraixet a penes apareix esmentat al Llibre del Repartiment-tal vegada per la fragmentarietat d'aquesta font (Baydal \& Esquilache 2020: 34-35)-, amb posterioritat les mencions documentals al seu terme esdevenen més usuals i, no debades, apareix com a nucli de població en una llista de «lochs e alqueries del terme e orta de València» feta el 1351 i, segons la ja esmentada font de l'impost del morabatí, el 1379 hi vivien fins a deu caps de família (Baydal \& Esquilache 2020: 59-68 i 100-113). Així mateix, Macarella no només apareix amb molta profusió al Llibre del Repartiment-hi ha setze esments-, sinó que, a més a més, és registrada igualment com a lloc de població de l'horta de València en la llista del 1351, i en el morabatí del 1379 s’indica que hi residien almenys set caps de família. ${ }^{9}$ Per contra, Xilvella, com hem vist, és mencionada de manera molt fugaç al Llibre del Repartiment i, sobretot, ni apareix en la llista del 1351 ni en la del 1379 com a lloc de poblament consolidat,

8 En Baydal \& Esquilache (2020: 15-41) vam considerar que l'horta del mig era Macarella -i no Xilvella, com afirmem ací- perquè la séquia que la rega rep el nom de braç de Macarella, però els nombrosos indicis documentals que hem trobat fent aquesta investigació apunten que aquella horta era, per contra, la de Xilvella, prop de Meliana i Almàssera, com veurem després, mentre que l'horta de més al nord era la de Macarella, fitant amb Foios. De fet, a banda de la partida contemporània de Macarella o «els Franchs de Macarella» de Foios (El Comercio: diario de Valencia, 6 de desembre de 1880, p. 3), ja en el segle XIV hem pogut documentar la venda d'un tros de terra del mateix terme de Foios que just fitava amb el "termino de Macharella, cequia in medio": ARV, Protocols notarials, 2.875 (Pasqual Vall-llebrera), 24 de març de 1329.

9 Vegeu les dades del 1351 i 1379 a: Arxiu Municipal de València, Manuals de Consells, A-10, ff. 52v-55v (14-XII1351); ARV, Mestre Racional, 11.769, ff. 24r-v (1379).

SCRIPTA, Revista internacional de literatura i cultura medieval i moderna, núm. 16 / desembre 2020 / pp. 24 - 39 ISSN: 2340-4841 · doi:10.7203/SCRIPTA.16.19228 
al contrari que Carraixet i Macarella, la qual cosa apunta al fet que després de la conquesta cristiana degué desaparéixer com a nucli de concentració d'habitatges i es va convertir en una menuda explotació agrària dins del reialenc del terme de la ciutat, és a dir, en una alqueria en el sentit cristià, tal com Ramon Muntaner dona a entendre que era la seua possessió rural de l'horta de València.

No debades, una recerca feta en els protocols notarials conservats a l'Arxiu del Corpus Christi de València i a l'Arxiu del Regne de València d'una selecció de notaris dels segles XIV al XIX indexats com a ubicats en les principals poblacions de la zona mostra la mateixa imatge: per bé que els nuclis i els termes de Carraixet/ Bonrepòs i Mirambell i Macarella són esmentats en desenes i desenes de documents al llarg de les centúries, les aparicions de la Xilvella/Xirivella d'aquesta part de l'horta de València són, per contra, escassíssimes i molt puntuals, segurament com a resultat de la seua conversió en època cristiana en una alqueria unifamiliar $\mathrm{i}$ una petita partida agrícola. ${ }^{10}$ Però, en qualsevol cas, les poques dades trobades són les que, de fet, indueixen a pensar que amb tota probabilitat l'«alqueria mia per nom Xilvella» de Muntaner pertany justament a aquesta zona. Concretament, dos han estat els moments i els notaris en què hem trobat informacions al respecte: un en la dècada del 1430, amb el notari Bertomeu Tovia, i un altre en la del 1700, amb el notari Josep Mora. I els dos ofereixen dades que concorden no només amb les paraules en primera persona de la crònica de Ramon Muntaner, sinó també amb el testament del seu fill, Macari Muntaner, publicat el 1394.

Primerament, com es pot observar en la Taula 1, Bertomeu Tovia va registrar entre el 1433 i el 1439 onze operacions diferents que, analitzades en conjunt, semblen fer referència a huit possessions diverses que, per ordre cronològic, es corresponien amb: 2 cafissades de terra campa, 1,75 cafissades de terra campa, cert tros de vinya mallol, 3 cafissades de terra campa, cert tros de terra campa, cert hort, 1 cafissada de vinya mallol i 2 cafissades de vinya. I totes elles estaven situades dins d'una zona de l'horta de València - «in orta Valentie»- que era anomenada Xilvella de Meliana: «in termino vulgariter nuncupato de Chilvella de Meliana», «in termino qui dicitur de Chilvella de Meliana», «in termino de Chilvella de Meliana», «in termino loci qui dicitur de Chilvella de Meliana», «in termino loci de Chilvella de Meliana» o «en terme de Chilvella de Meliana». Per tant, sembla evident que aquelles terres es trobaven en una àrea que estaria al costat o en les immediacions de l'antiga horta andalusina de Xilvella al-Xarquia, just tocant amb el terme de Meliana, segons es pot observar en la Figura $3 .{ }^{11}$ De fet, en relació amb això, cal indicar que les

$10 \mathrm{Hem}$ consultat els següents protocols de notaris que, segons els corresponents índexs arxivístics, treballaven a Meliana, Foios o Bonrepòs i Mirambell: ACCV, Protocols notarials, 50 i 51 (Joan de Santfeliu), 1.353 (Francesc Arinyo), 1.432 (Nicolau Menor), 2.699 (Domingo de Molinos), 6.448 (Andreu Cirera), 20.155, 20.156, 20.158, 20.159, 20.160, 20.161 i 20.162 (Lluís Tovia) 20.620 (Andreu Cirera), 22.821 i 22.824 (Pere Ferrer), 24.143 (Joan Verdancha), 24.288 (Cristòfol Fabra), 24.537, 24.538, 24.539, 24.540, 24,541, 24,542, 24,543, 24.544, 25.043, 25.045, 25.046, 25.047, 25.048, 25.049, 25.050 i 25.051 (Bertomeu Tovia), 25.308 i 25.309 (Bertomeu Matoses), 25.868 i 25.869 (Joan de Santfeliu), 26.680 (Joan de Carcî), 27.081 i 27.086 (Bernat Julià); ARV, Protocols notarials, 2.002 (Guillem Tovia), 2.820 (Arnau de Casesvelles), 2.833, 2.875 i 4.231 (Pasqual Vall-llebrera)-dels segles XIV i XV-; APPV, Protocols notarials, 10.281 (Lluís Castelló), 13.210 (Jeroni Espinsola), 13.986 (Francesc Joan Alçamora), 15. 694 (Joan Monterde), 18.899 (Jaume Salt), 21.184 i 21.188 (Jeroni Godos), 24.306, 24.307 (Cristòfol Fabra), 24.338 i 24.340 (Josep Mora), 27.211 (Joan Frechina); ARV, Protocols notarials, 585 (Pere Coblliure), 704 (Miquel Daviu), 1.128 (Joan Gilabert), 1.564 (Josep Mora) -dels segles XVI i XVII-; APPV, Protocols notarials, 24.361 (Josep Mora); ARV, Protocols notarials, 5.394 (Ramon Conejos), 7.490 (Manuel Polart), 9.906 (Juan Bautista Ronda) -dels segles XVIII i XIX. Als esmentats arxius hi ha encara molts més notaris indexats en eixes poblacions, però hem considerat que la recerca feta era suficientment representativa per a poder obtindre informacions i establir diferències entre els principals topònims de la zona que eren objecte de la nostra investigació: Carraixet/Bonrepòs i Mirambell, Nacarella/Macarella i Xilvella/Xirivella.

11 Tot i que, com hem citat i es pot observar en la Taula 1, hi ha un parell de referències al «loci de Chilvella de Meliana»

SCRIPTA, Revista internacional de literatura i cultura medieval i moderna, núm. 16 / desembre 2020 / pp. 24 - 39 ISSN: $2340-4841 \cdot$ doi:10.7203/SCRIPTA.16.19228 
confrontacions assenyalades coincidien reiteradament amb el Camí Reial de Morvedre i en menor mesura amb una altra via pública que era el camí que duia a Meliana, que també es pot veure en l'esmentada Figura. Així mateix, cal remarcar també que les quantitats de terra transmeses en les esmentades operacions, que feien 9,75 cafissades, dos trossos de terra i un hort, és a dir, poc més de 4,8 hectàrees, són perfectament encaixables en aquesta zona, en la qual les terres estaven sotmeses al pagament d'un cens anual al ciutadà de València Lluís de Cruilles i un benefici de la catedral instituït per Magdalena de Mompalau, viuda del cavaller Acard de Mur, que possiblement havien adquirit alguns lots de terres franques de reialenc-com ho eren les de Xilvella i les de Meliana- per tal d'arrendar-les amb posterioritat.

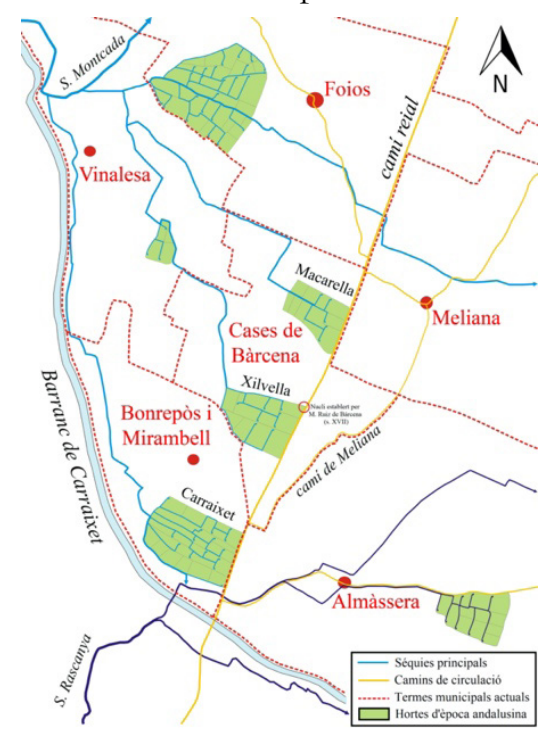

Figura 3. Hortes d’època andalusina al voltant de les Cases de Bàrcena i límits dels termes municipals actuals de la zona.

D'una altra banda, les informacions proporcionades per l'altre esment notarial que hem localitzat, tot i ser molt posterior, del 1703, més de dos segles i mig després, indiquen tres aspectes importants. Primerament, que l'àrea anomenada Xilvella continuava existint, ara amb l'evolució lingüística del topònim pròpia d'època moderna: «in partita nuncupata de Chirivella». Segonament, que en ella hi havia almenys una alqueria unifamiliar amb 9 cafissades o 4,5 hectàrees, la del notari Joan Bòria, que confrontava amb l'রitinere del Girant loci de Meliana», és a dir, amb la via que duia a l'esmentada localitat per la part oriental del Camí Reial de Morvedre, que certament fa uns particulars girs, segons es pot apreciar en l'esmentada Figura 3. Finalment, en tercer lloc, el mateix document indicava que aquesta partida anomenada de «Chirivella» pertanyia al terme municipal de València, ja que es trobava «in territorio de les Cases de Bàrcena», que, com explicarem en l'apartat següent, va ser el nom que va començar a rebre aquesta part d'horta de la ciutat a partir del segle XVII. Però si alguna cosa destaca per damunt de tot en aquest conjunt de documents de les dècades del $1430 \mathrm{i}$ el 1700 per a l'afer que ens ocupa és la manera dels notaris d'anomenar la zona, clarament anàloga a la que va emprar el notari Jaume Mestre en la publicació del testament de Macari Muntaner, fill i hereu del cronista, com ara veurem.

no sembla, en conjunt, que hi hagués realment un lloc o poblat, sinó una partida amb diversos trossos de terra. De fet, fins i tot en el document del 21 de juny del 1436 la paraula lloc apareix ratllada pel notari: «in termino toci de Chilvella de Meliana, orte Valentie». 
No en va, segons la còpia realitzada pel justícia civil de València el 1607 de l'esmentat testament, Mestre el va publicar el 8 d'octubre del 1394 a instàncies de la dona de Macari, Corsa Espanyola de Cervató, «in quadam rure sita et posita in horta Valentie, vulgariter nuncupata Chilvella». ${ }^{12}$ En aquest sentit, com ja va indicar Mateu Rodrigo (2019: 41-42), tot i que Francesc Almarche (1909: I, doc. XII) va transcriure «in quadam turre», la còpia indicada diu clarament «in quadam rure», del llatí rus, casa de camp o possessió rural, la qual cosa, en tot cas, no afecta a l'evident coincidència amb els altres esments notarials que hem vist a l'hora de fer referència al terme o partida de Xilvella/Xirivella que es trobava en l'horta de la ciutat de València, al seu nord, tocant amb Meliana i el Camí Reial de Morvedre. Sembla evident, doncs, que la «quadam rure sita et posita in horta Valentie, vulgariter nuncupata Chilvella», on encara residien Macari Muntaner i la seua esposa a final del segle XIV, no es tractava de la localitat de Xirivella de l'Horta Sud, sinó d'una petita explotació agrària a la Xilvella de l'Horta Nord, l'«alqueria mia per nom Xilvella, que és en la orta de València», a la qual feia referència son pare en la crònica. ${ }^{13}$

És ben probable, en relació amb això, que a l'alçada del 1325, quan Ramon Muntaner comença a redactar la seua obra, l'antic nucli i horta andalusina de Xilvella haguera donat lloc a una alqueria dita així, que, a més a més, també donaria nom al conjunt de la partida o terme conformat per les terres properes a un costat i l'altre del Camí Reial de Morvedre. En aquest sentit, tot allò que són desajustos i contradiccions en la identificació per al segle XIV de l'alqueria de Muntaner amb la Xirivella meridional són ajustos i coherències en la identificació amb la Xilvella septentrional: seria una alqueria, casa de camp o explotació agrària unifamiliar; en aquells moments seria propietat directa del cronista per complet, amb el nom conjunt de Xilvella; i, a més a més, es trobaria dins de l'horta pertanyent al mateix terme municipal de la ciutat de València. És totalment lògic, doncs, que, amb plena exactitud, Muntaner escrivís les paraules que coneixem de la seua crònica. La confusió, no obstant això, es començaria a produir més tard, a partir del moment en què des de la segona meitat del segle XV i principi del XVI, probablement per una errada ocasionada per una mala interpretació de la crònica i per la mateixa petitesa de la Xilvella septentrional, es va començar a considerar Ramon Muntaner com a senyor d'un nucli més important, la Xirivella meridional.

\section{De Xilvella i Macarella a les Cases de Bàrcena, una pedania de la ciutat de València}

A l'evident oblit historiogràfic de la Xilvella del nord i la consegüent manca d'identificació amb l'alqueria de Ramon Muntaner han contribuit probablement dos factors: el fet que pertanyera a una petita àrea rural perifèrica de València, que com la majoria de nuclis històrics tradicionals de la ciutat no ha rebut a penes atenció a causa de la dedicació preeminent a altres aspectes generals del municipi, i, igualment, el fet que el nom de la partida passara desapercebut en època contemporània, amb la corresponent desaparició del marc de treball dels autors que han tractat la qüestió. En relació amb això, també volem fer ací un breu avanç de la investigació que hem dut a terme sobre l'evolució general del poblament de la zona que en l'actualitat forma la pedania de les Cases de Bàrcena, pertanyent al districte municipal dels Poblats del Nord de València, en la qual, com hem vist, es trobava amb molta probabilitat l'alqueria que van posseir Ramon i Macari Muntaner.

12 ARV, Manaments i empares, Any 1607, Llibre 9, mà 85, ff. 32r-37r.

13 Hem cercat sense èxit el testament original de Macari Muntaner entre els llibres conservats del notari Jaume Mestre a l'Arxiu del Regne de València i l'Arxiu del Corpus Christi de València, que hem consultat per complet entre els anys 1385 i 1405. 
En aquest sentit, segons s'observa en la Figura 3, dins de l'actual pedania de les Cases de Bàrcena es poden identificar les dos hortes històriques d'origen andalusí que hem comentat: les de Xilvella/Xirivella i Macarella, que van donar nom a dos termes rurals que ja hem vist adjacents en el moment de la conquesta de Jaume I el 1238. Amb tot, com també hem apuntat, mentre que Xilvella després de l'ocupació cristiana no va existir com a nucli de població concentrat, ja que segurament va esdevindre una simple alqueria i partida, no va passar el mateix amb Macarella, que es pot documentar a bastament com a lloc de poblament dins del terme de València, amb una comunitat rural, al llarg del segle XIV. ${ }^{14}$ No obstant això, tot indica que durant la següent centúria va deixar d'existir com a nucli concentrat de residència, atés que ja no apareix en les llistes fiscals del morabatí, la qual cosa no va impedir que les terres de la zona continuaren rebent el mateix nom, com així apareix en abundants referències notarials de l'època a parcel les ubicades en el «termino et partita de Macarella», posseïdes fonamentalment per habitants de les localitats veïnes de Foios, Vinalesa i Meliana. ${ }^{15}$

D’una altra banda, sabem que més avant, cap al final del segle XVI, el mercader de Burgos arribat a València Marco Ruiz de Bárcena (c. 1550-1614) va posseir una «alqueria gran» sobre el Camí Reial de Morvedre i sembla que entorn de la dècada del 1600, quan també va assolir els importants càrrecs de racional de la ciutat i clavari i diputat de la Generalitat pel braç reial, va dur a terme un projecte d'establiment de llauradors en un seguit de cases noves construïdes just en el límit nord de l'antiga horta de Xilvella, segons es pot observar en les Figures 3 i 4, on encara hi ha en l'actualitat els nuclis d'habitatge més antics de la pedania de les Cases de Bàrcena. ${ }^{16}$ No en va, uns pocs anys després de la mort de Marco Ruiz de Bárcena, el 1623, es documenten fins a nou hereters arrendats: un en l'esmentada «alqueria gran» i huit més en altres «cases del Camí Real», amb terres en la zona que havia adquirit el mateix mercader i que continuaven pertanyent al terme de València. ${ }^{17}$ En aquest mateix sentit, per bé que en les llistes del morabatí del 1602 el nucli no apareix encara, en les següents disponibles, les del 1620, són ja esmentades l'alqueria i deu cases més - tot i que quatre d'elles es registraven com a «casa nova tancada buyda», segurament per certes dificultats en el procés de població $\mathrm{i}$ establiment dels llauradors. ${ }^{18}$

14 A més de les evidències anteriorment citades de Macarella com a nucli de població el 1351 i el 1379, també es poden trobar molts altres esments notarials als seus veïns o terres del terme durant els segles XIII i XIV, per exemple a: Arxiu de la Catedral de València, Pergamins, núm. 1.146 (22-I-1295), 6.306 (4-III-1295), 6.310 (30-VIII-1296) i 6.312 (9-II-1297); ARV, Protocols notarials, 2.833, 2.875 i 4.231 (Pasqual Vall-llebrera), pàssim; Archivo Histórico Nacional, Clero-Secular regular, carpeta 467, núm. 5 (13-XI-1383). Després de les llistes de poblacions del morabatí del 1379 les següents disponibles són les del 1415, on Macarella ja no apareix com a lloc de residència consolidat: ARV, Mestre Racional, 10.870 (1415).

15 Se'n poden trobar contínuament des del segle XV i al llarg de tota l'edat moderna: APPV, Protocols notarials, 25.045 (Bertomeu Tovia), 21 de febrer del 1455; 25.050 (Bertomeu Tovia), 24 de febrer del 1459; 26.680 (Joan de Carcí), 18 d'abril del 1471; 6.448 (Andreu Cirera), 16 de febrer del 1477; 20.162 (Lluís Tovia), 17 d'agost del 1481 i 13 d'octubre del 1481; 21.188 (Jeroni Godos), 17 de febrer del 1630; 27.211 (Joan Frechina), 26 de maig del 1670; 24.361 (Josep Mora), 1 de novembre del 1703; ARV, Protocols notarials, 5.394 (Ramon Conejos), 3 de maig del 1795.

16 Les dades biogràfiques de Marco Ruiz de Bárcena es poden extraure d’un seguit de causes judicials relacionades amb els seus diversos càrrecs públics: ARV, Reial Audiència, Processos, Part I, Lletra S, núm. 836 (1587); Part III, Apèndix, núm. 7087 (1604); Processos de Madrid, Lletra L, exp. núm. 156 (1593); Lletra M, exp. 335 (1604). També se'n poden trobar certes informacions en sengles obres d'Amparo Felipo (2002: 26, 66-81, 119, 180, 189, 224, 225, 278-281, 301, 318, 226, 346 i 347) i Francisco Mayordomo (2002: 142, 156 i 169).

17 Les dades es poden trobar en un procés judicial iniciat entorn de la curatela de la seua filla i hereva Margarida Vicenta Bàrcena: ARV, Reial Audiència, Processos, Part I, Lletra A, núm. 1.203 (1623).

18 ARV, Mestre Racional, 10.898 (1602); 11.813, f. 382r (1620).

SCRIPTA, Revista internacional de literatura i cultura medieval i moderna, núm. 16 / desembre 2020 / pp. 24 - 39 ISSN: $2340-4841 \cdot$ doi:10.7203/SCRIPTA.16.19228 
A més a més, en la mateixa font del morabatí aquella nova instal lació era ja denominada com «les Cases de davant Marco Roys de Bàrzena», les «Cases de Marco Ruy, dites de Bàrcena» o, simplement, «les Cases de Bàrcena», el nom que rebria la zona a partir de llavors, incloent amb el temps el terme veí i juxtaposat de Macarella, que pertanyia igualment a la ciutat de València. ${ }^{19}$ Amb tot, la divisió entre les dues zones de Xilvella/Xirivella i Macarella, que, com hem vist, procedia d'època andalusina, va continuar, especialment per a les qüestions relatives al reg, ja que marcaven sengles particions hidràuliques de la Reial Séquia de Montcada. Així, per exemple, en una «memòria del gasto que serà fet per a adobar los partidors del bras de Macarella y del bras dels Moros» del 1646 s'incloïa el que havien de pagar els hereters que regaven «en Binalesa, en los Franchs, en Macarella, en Girivella», alhora que en un conflicte sobre l'ús dels cabals hídrics generat el 1738 els síndics de la Séquia es van reunir per tal de «veure com avien de regar los (...) de la fila de Miliana, de Vinalesa, Macarella y Girbella», una enumeració que segurament es feia de nord a sud. ${ }^{20}$ En aquest sentit, una altra referència, ja de 1883, indica que existia un «brazo de Chirivella» per al qual es nomenava un «atandador» encarregat de distribuir l'aigua de reg, triat pels hereters de la zona, «más de cuarenta vecinos de los términos municipales de Valencia y Almácera», mitjançant una votació que comptava amb la presència de l'alcalde pedani de les Cases de Bàrcena i de l'alcalde de la mateixa població d'Almàssera, la qual cosa indica la posició meridional de la partida. ${ }^{21}$

No obstant això, com es pot observar en el detallat estudi de Vicent Sales (2015: 92-93) sobre els regadius històrics de la Séquia de Montcada, a partir de 1940 aquelles particions hidràuliques van deixar de funcionar i tant Xirivella com Macarella van passar a ser gestionades i denominades conjuntament com les Cases de Bàrcena, raó per la qual segurament Xirivella ha desaparegut per complet de la toponímia de la zona i cap dels molts llauradors als quals hem fet entrevistes orals sobre la qüestió en tenia ja coneixement, ni es pot trobar en els mapes i descripcions topogràfiques contemporànies. Macarella, per contra, d'acord amb la seua preeminència documental històrica, sí que s'ha conservat com un nom identificable pels habitants de la contornada, atés que no només continua denominant un braç de la Séquia, sinó que, a més a més, existeixen partides de Macarella a Vinalesa i Foios i una senda de Macarella que connecta la mateixa població de Foios amb Bonrepòs i Mirambell passant pel terme de les Cases de Bàrcena. En relació amb això, és possible fins i tot que l'aparició d'aquest darrer topònim acabara desplaçant totalment el de Xirivella, atés que les seues edificacions s'ubicaven allà mateix, i, de fet, si bé a final del segle XVIII el geògraf Antoni Josep Cavanilles (1795: I, 140) encara parlava conjuntament de Macarella i de «los caseríos de Chirivella», mitja centúria després, per contra, Pascual Madoz (1845-1850: IX, 513; XV, 412) ja només esmentava Macarella com a aldea rural pertanyent al terme municipal de València amb un grup d'edificacions i barraques disseminades per la zona, a excepció de les Cases de Bàrcena pròpiament dites, «que estan unidas a der. é izq. de la carretera de Barcelona» i que probablement, com hem vist, es corresponien amb l'antiga horta i terme de Xilvella/Xirivella.

19 ARV, Mestre Racional, 11.813, f. 382r (1620); 11.816, f. 342r (1638); 11.817, f. 278r (1644).

20 Arxiu de la Reial Séquia de Montcada, Administració, Sequiatge (obres), 1646, citat per Frechina, Sales, Mangue \& Ferrer (2007: 142); Arxiu de la Reial Séquia de Montcada, Difinicions 1730-1739, f. 155v, citat per Peris Albentosa (2019: 322).

21 AMV, Policia rural, Séquia de Montcada, Secció 3a/B71 (any 1883), citat per Sales (2015: 170). També Ramon Ruipérez (2016), en un treball sobre la toponímia de Meliana, vincula Xilvella a la zona de contacte entre l'esmentada localitat i la part oriental del terme de les Cases de Bàrcena. 
En consonància amb això, de fet, el ben cert és que, més enllà de les qüestions relatives a la irrigació, el topònim de Xilvella/Xirivella és realment escàs en la documentació, la qual cosa concorda plenament amb el que hem observat sobre l'evolució històrica de la primigènia Xilvella al-Xarquia i la seua conversió en època cristiana en una petita àrea o explotació rural. Era ací on segurament es trobava l'«alqueria mia per nom Xilvella» de Ramon Muntaner cap al 1325, que encara el 1394, en la publicació del testament del seu fill, era denominada com a «rure» o possessió rústica «vulgariter nuncupata Chirivella», la qual probablement s’ubicaria prop del Camí Reial de Morvedre, on hi havia hagut l'antiga horta andalusina. I era també per aquesta zona on diversos trossos de terra que fitaven amb el mateix Camí Reial i el terme i camí de Meliana -la «Chilvella de Meliana»- eren comprats i venuts en la dècada del 1430; on en el segle XVII el mercader Marco Ruiz de Bárcena va instal lar al costat de la seua alqueria un nou nucli de població, que va acabar prenent el seu nom fins a hui en dia; i on a començament del segle XVIII s'ubicava també una altra alqueria, la de Joan Bòria, «in partita nuncupata de Chirivella», amb una explotació agrícola que fitava igualment amb el camí de Meliana.

En definitiva, per tot el que hem explicat, fins a cert punt és lògic que aquesta fugissera Xirivella, l'antiga Xilvella al-Xarquia, més tard amagada junt amb Macarella dins del topònim de les Cases de Bàrcena i del gran terme municipal de la ciutat de València, no haja estat històricament presa en consideració a l'hora d'identificarla amb el lloc on comença la crònica de Ramon Muntaner. Ara, però, sembla que ja no hi ha excusa.

\section{Conclusions}

Segons hem vist, malgrat que ja des de la segona meitat del segle XV hi hagué indicacions que consideraven Ramon Muntaner com a «senyor de Chilvella» i que, en conseqüència, tradicionalment s'ha vinculat la seua figura i l'inici de la seua crònica a l'actual municipi de Xirivella, al sud de València, aquesta identificació sempre havia generat alhora certes reticències, ateses les proves documentals que la desmentien. En concret, se sabia i se sap que abans, després i en vida de Muntaner la senyoria de la localitat la va exercir l'orde militar de Calatrava, per la qual cosa les úniques opcions per a explicar la seua possible connexió amb el municipi serien que haguera arribat a algun tipus d'acord de cessió temporal del senyoriu, que mai s'ha pogut demostrar -ni acaba d'encaixar amb la trajectòria del cronista-, o que només hi tinguera una possessió unifamiliar dins del terme, i no tot el lloc, la qual cosa divergiria de les paraules que va deixar escrites amb claredat: «una alqueria mia per nom Xilvella». Per contra, totes les contradiccions desapareixen si considerem que aquesta alqueria no era l'actual municipi de Xirivella, sinó una àrea rural al nord del terme de la ciutat de València, la de Xilvella al-Xarquia, segons era anomenada en el moment de la conquesta cristiana de Jaume I el 1238.

En aquest sentit, certament no hem trobat cap document que ubique directament la Xilvella dels Muntaner en aquesta zona concreta, que es trobava ubicada entre els termes de Carraixet/Bonrepòs i Mirambell, Almàssera, Vinalesa, Macarella i Meliana, però tots els indicis documentals així ho apunten i cap d'ells ho desmenteix. En primer lloc, perquè, com hem vist, en aquest cas és ben probable que la Xilvella al-Xarquia sí que haguera esdevingut a començament del segle XIV una alqueria o petita explotació rural dita Xilvella, en consonància amb les paraules de la crònica. I en segon lloc, sobretot, per la coincidència a l'hora d'anomenar la possessió dels Muntaner l'any 1394 com a «rure sita et posita in horta Valentie, vulgariter nuncupata 
Chilvella», i l'esmentada zona com a «in orta Valentie, termino vulgariter nuncupato de Chilvella de Meliana» en la dècada del 1430 i encara com a «partita nuncupata de Chirivella» el 1703. A més a més, la possessió d'una menuda alqueria o domini agrícola dins del terme de València encaixa plenament amb la trajectòria socioeconòmica del cronista i amb la seua possessió d'altres modestes propietats rurals.

En relació amb això, també hem mostrat l'evolució general d'aquesta àrea, que probablement després de la possessió dels Muntaner es va dividir en diverses parcel les de terra en mans d'hereters que residien en altres llocs. Amb tot, el nom de Xilvella, evolucionat en època moderna a Xirvella i Xirivella, es va mantindre, especialment per a qüestions de reg, encara que possiblement va ser desplaçat com a topònim general a causa de la instal lació d'un nou nucli de poblament allà mateix, el que va crear a principi del segle XVII entorn del Camí Reial de Morvedre el mercader castellà Marco Ruiz de Bárcena, que va acabar rebent la denominació de les Cases de Bàrcena, incloent la zona adjacent de Macarella, com un illot pertanyent al terme de la ciutat de València en aquesta part de l'Horta Nord. En síntesi, doncs, el més probable és que l'inici de la crònica de Ramon Muntaner tinguera lloc en aquesta Xilvella septentrional, en l'alqueria que el cronista segurament posseïa dins de l'actual pedania de les Cases de Bàrcena.

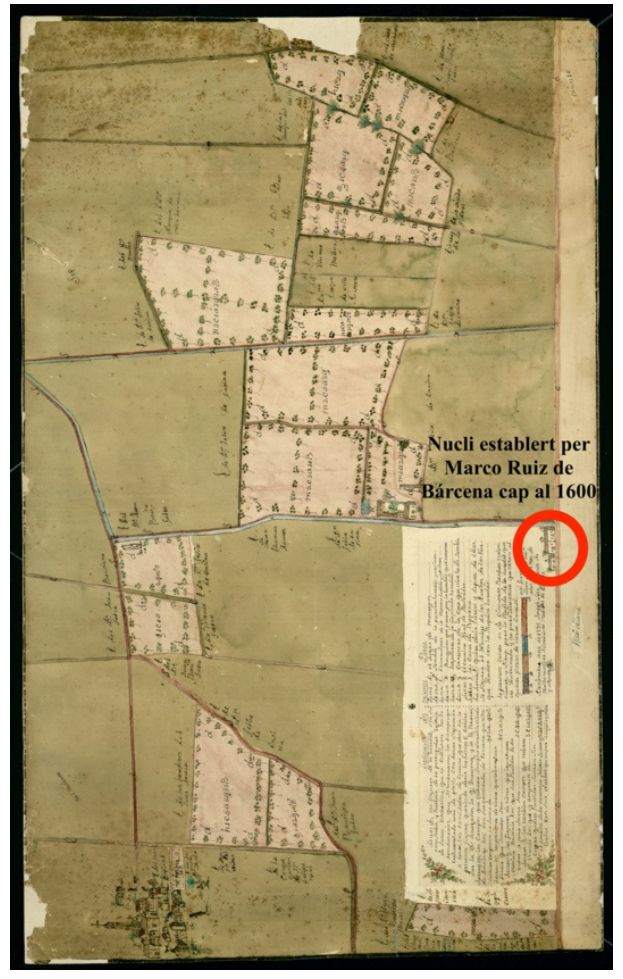

Figura 4. Mapa del 1790 de la zona occidental de l'actual terme de les Cases de Bàrcena, que inclou un dibuix del nucli instal lat per Marco Ruiz de Bárcena sobre el Camí Reial de Morvedre cap al 1600. Font: Arxiu del Regne de València, Mapes i plànols, núm. 37. 
Vicent Baydal \& Ferran Esquilache. Una nova proposta d'identificació de l'«alqueria mia per nom Xilvella» de la crònica de Ramon Muntaner: les Cases de Bàrcena, al nord de la ciutat de València

\section{Bibliografia}

Aguilar, J. A. (2015): La Crònica de Ramon Muntaner: edició i estudi (Pròleg-cap. 146), Barcelona, Institut d'Estudis Catalans, 2 vol.

Almarche, F. (1909): «Ramón Muntaner, cronista dels reys de Aragó, ciutadà de València», dins I Congrés d'Història de la Corona d'Aragó, Barcelona, Ajuntament de Barcelona, pp. 483-505.

Baydal, V. \& Esquilache, F. (2020): De Carraixet a Bonrepòs i Mirambell. Els orígens medievals d'un poble valencià, València, Institució Alfons el Magnànim - Centre d'Estudis i Investigació.

Beuter, P. A. (1538): Primera part de la història de València, València, Joan Mey.

Bofarull, P. (1883): Ramón Muntaner, guerrero y cronista, Barcelona, Establecimiento tipográfico de los sucesores de N. Ramírez.

Bolós, J. (1993-1994): «Aportació al coneixement de les terres de conreu a Catalunya a l’Edat Mitjana», Acta historica et archaeologica mediaevalia, 14-15, pp. 143-174.

Cavanilles, A. J. (1795): Observaciones sobre la bistoria natural, geografía, agricultura, población y frutos del Reyno de Valencia, Madrid, Imprenta real, 2 vol.

Cingolani, S. (2015): Vida, viatges i relats de Ramon Muntaner, Barcelona, Base.

Diago, F. (1613): Anales del Reyno de Valencia, València, Pedro Patricio Mey.

Epalza, M. (1988): «L'ordenació del territori del País Valencià abans de la conquesta, segons Ibn al-Abbar (segle XIII)», Sharq al-Andalus. Estudios Árabes, 5, pp. 41-68

Eritja, X. (1998): De l'Almunia a la Turris: organització de l'espai a la regió de Lleida (segles XI-XIII), Lleida, Universitat de Lleida.

Escolano, G. (1611): Segunda parte de la Década primera de la historia de la insigne y coronada ciudady reyno de Valencia, València, Pedro Patricio Mey.

Esquilache, F. (2016), «Les hortes de Xirivella i Andarella en època medieval. Dos exemples de colonització feudal en el paisatge de l'Horta Sud», Annals de l'Institut d'Estudis Comarcals de l'Horta Sud, 9, pp. 67-85.

Felipo, A. (2002): La oligarquía municipal de la ciudad de Valencia. De las Germanias a la insaculación, València, Institució Alfons el Magnànim.

Ferrando, A. (ed.) (1979): Llibre del Repartiment de València, València, Vicent García Editors.

Frechina, J. V., Sales, V., Mangue, I. \& Ferrer, A. (2007): Vinalesa. Geografia, bistòria i patrimoni d'un poble de l'Horta, Vinalesa, Ajuntament de Vinalesa.

Guichard, P. (2001): Al-Ándalus frente a la conquista cristiana: los musulmanes de Valencia (siglos XI-XIV), Madrid/ València, Biblioteca Nueva/Universitat de València.

Guinot, E. (2007): «El repartiment feudal de l'Horta de València al segle XIII: jerarquització social i reordenació del paisatge rural», dins Guinot, E. / Torró, J. (eds.): Repartiments medievals a la Corona d'Aragó, València, Publicacions de la Universitat de València, pp. 115-199.

Madoz, P. (1845-1850): Diccionario geográfico-estadístico-bistórico de España y sus posesiones de Ultramar, Madrid, Imprenta del Diccionario geográfico-estadístico-histórico de D. Pascual Madoz.

Mayordomo, F. (2002): La Taula de Canvis. Aportación a la bistoria de la contabilidad valenciana (siglos XIII-XVII), València, Publicacions de la Universitat de València.

Peris Albentosa, T. (2019): «Gestionar la irregularidad hídrica. Policultivo intensivo, flexibilidad operativa y adaptación organitzativa en la acequia de Montcada (huerta de Valencia) durante los siglos XIII-XIX»,

SCRIPTA, Revista internacional de literatura i cultura medieval i moderna, núm. 16 / desembre 2020 / pp. 24 - 39 
Vicent Baydal \& Ferran Esquilache. Una nova proposta d'identificació de l'«alqueria mia per nom Xilvella» de la crònica de Ramon Muntaner: les Cases de Bàrcena, al nord de la ciutat de València

dins Vicedo, E. (ed.): Recs històrics: pagesia, història i patrimoni. IX Congrés sobre sistemes agraris, organització social i poder local, Lleida, Institut d'Estudis Ilerdencs, pp. 287-344.

Ribera, J. (1952): Opúsculos dispersos, Tetuan, Instituto General Franco de Estudios e Investigación HispanoÁrabe.

Riu, M. (1996): «Pesos, mides i mesures a la Catalunya del segle XIII: aportació al seu estudi», Anuario de Estudios Medievales, 26, pp. 825-837.

Rodrigo, M. (2019): «Ramon Muntaner i la ciutat de València», dins Aguilar, J. A. / Martí, S. / Renedo, X. (eds.): Dits, fets i veres veritats. Estudis sobre Ramon Muntaner i el seu temps, Barcelona, Publicacions de l'Abadia de Montserrat.

Ruipérez, R. (2016): «Toponímia de Meliana», dins Actes de la IX Jornada d’Onomàstica. Mislata 2015, València, Acadèmia Valenciana de la Llengua.

Sales, V. (2015): Las ampliaciones modernas en los regadios históricos. Jovedaty Extremal de la Real Acequia de Moncada, València, Universitat Politècnica de València, Tesi doctoral inèdita.

Sarobe, R. (1998): «Deu establiments fets pels templers al Segrià durant l'any 1181», Urtx: revista cultural d'Urgell, 11, pp. 59-68.

Serrano Morales, E. (1898-1899): Reseña bistórica en forma de diccionario de las imprentas que han existido en Valencia desde la introducción del arte tipográfico basta el año 1868, con noticias bio-bibliográficas de los principales impresores, València, Federico Doménech. 
Vicent Baydal \& Ferran Esquilache. Una nova proposta d'identificació de l'«alqueria mia per nom Xilvella» de la crònica de Ramon Muntaner: les Cases de Bàrcena, al nord de la ciutat de València

Taula 1. Transmissió de possessions al terme o partida de Xilvella de Meliana/Xirivella de Cases de Bàrcena en les dècades del $1430 \mathrm{i}$ el $1700^{22}$

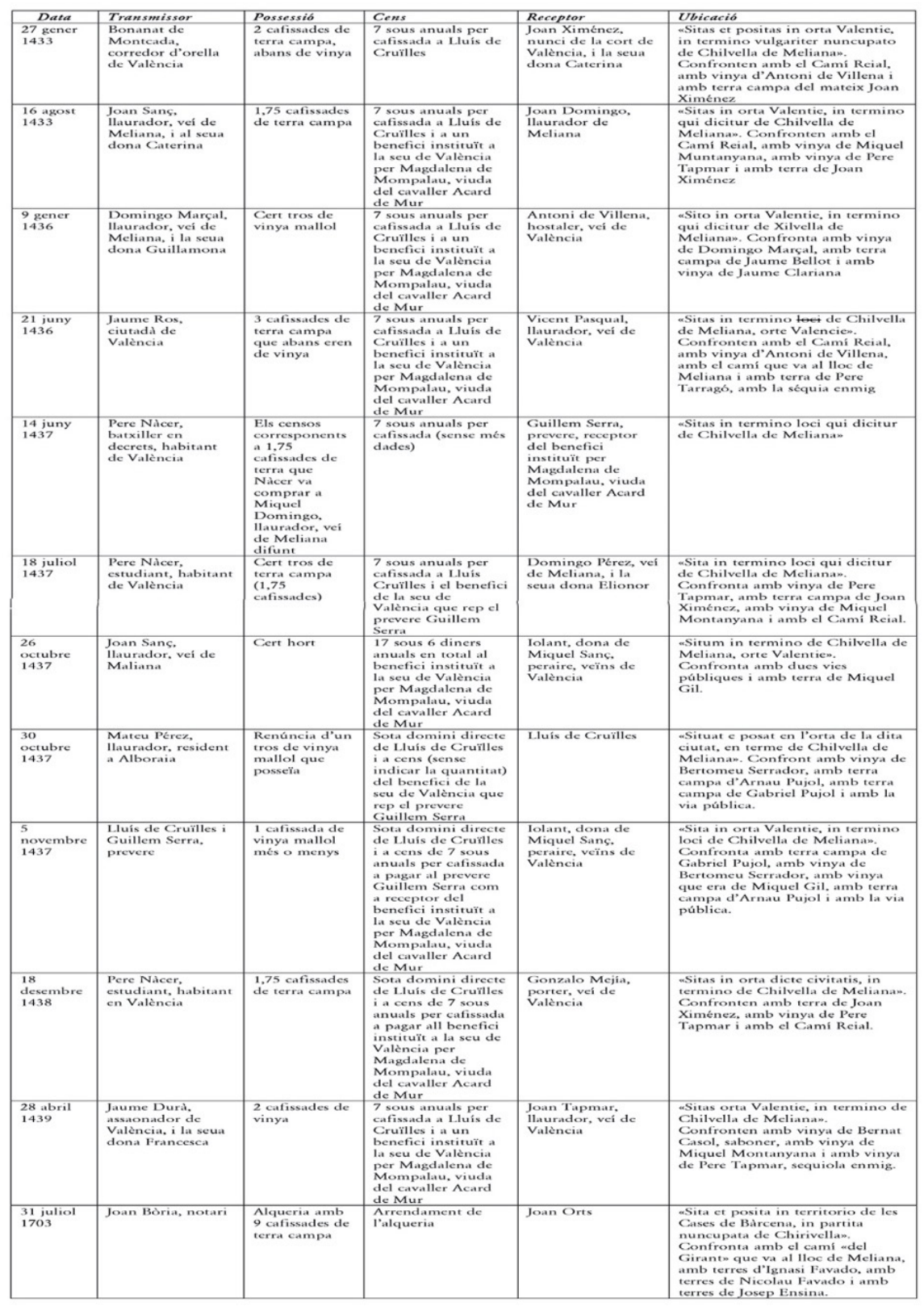

22 Dades extretes de: APPV, Protocols notarials, 24.537 (Bertomeu Tovia), 27 de gener del 1433 i 16 d'agost del 1433; 24.540 (Bertomeu Tovia), 9 de gener del 1436 i 21 de juny del 1433; 24.541 (Bertomeu Tovia), 14 de juny del 1437, 18 de juliol del 1437, 26 d'octubre del 1437, 30 d'octubre del 1437 i 5 de novembre del 1437; 24.542 (Bertomeu Tovia), 18 de desembre del 1438; 24.543 (Bertomeu Tovia), 28 d’abril del 1439; 24.361 (Josep Mora), 31 de juliol del 1703.

SCRIPTA, Revista internacional de literatura i cultura medieval i moderna, núm. 16 / desembre 2020 / pp. 24 - 39 ISSN: 2340-4841 · doi:10.7203/SCRIPTA.16.19228 